\title{
WATER CONSERVATION: A GLOBAL NEED
}

\author{
A. Verma ${ }^{* 1}$ (iD), P Shrivastava ${ }^{2}$, S B Nahatkar ${ }^{3}$ \\ ${ }^{1}$ Assistant Professor (English), IABM, JNKVV, Jabalpur, India \\ ${ }^{2}$ Assistant Registrar (Legal), IABM, JNKVV, Jabalpur, India \\ ${ }^{3}$ Director IABM, JNKVV, Jabalpur, India
}

DOI: https://doi.org/10.29121/granthaalayah.v8.i10.2020.1874

Article Type: Research Article

Article Citation: A. Verma, $\mathrm{P}$

Shrivastava, and S B Nahatkar. (2020). WATER CONSERVATION: A GLOBAL NEED. International

Journal of Research -

GRANTHAALAYAH, 8(10), 138-141. https://doi.org/10.29121/granthaa layah.v8.i10.2020.1874

Received Date: 30 September 2020

Accepted Date: 28 October 2020

Keywords:

Crisis

Wastewater

Preservation

\begin{abstract}
Water is the lifeline of any nation's richness and development. We should conserve water for future generations as it can be big trouble for the country. Since ancient times, the region of high prosperity for water resources was considered a subcontinent, but today like other countries of the world, India's water crisis problem, is vivid. India is the world's largest groundwater extractor, pumping about twenty-five percent of the world's groundwater use annually. Five of the world's 20 largest cities in water stress are in India, with Delhi in second place. India has 16\% of the world's population and only $4 \%$ of the world's water resources, which are rapidly reducing. Daily struggles for the fetching water, mismanagement of wastewater, improper sanitation are common features affecting human health and the economy of the nation indirectly. The situation calls for widespread intrusion in the management of this rapidly growing problem. The water crisis will not go away on its own. On the contrary, it will deteriorate until we respond as a global community and use water responsibly. Therefore, before it is too late, let us all pledge to use water wool as individuals, families, communities, companies, and institutions. Intelligence is not in elegance, but preservation so that our future generations can enjoy the joy and touch of water.
\end{abstract}

\section{INTRODUCTION}

"Managing water as an economic good is an important way of achieving efficient and equitable use, and of encouraging conservation and protection of water resources." (ICWE, 1992)

The five elements, which are present in the whole life through the universe, are water, air, fire, sky, and earth. Life cannot be imagined if one of these is removed even if the element is removed. Presently the water crisis is very deep. Today the value of water has changed and water has become an important and valuable commodity. While pure water is nectar on one side, contaminated water is the basis of the epidemic and other health issues. The life of a human passes through problems, but when the same problem comes every time in the same way, then the problem is caused by human error. So it can be said that the water problem is caused by human error. If we see urbanization and industrialization are necessary for the overall development of the country, on the other hand, both these factors are helpful in increasing the water problem. The water crisis is also a problem arising out of human error as human beings have been exploiting nature with the progress of civilization. Water resources, conservation, and promotion

(C) 2020 The Author(s). This is an open access article distributed under the terms of the Creative Commons Attribution License, which permits unrestricted use, distribution, and reproduction in any medium, provided the original author and source are credited. 
are the need of the day, in which public support is expected. The water crisis has taken a formidable form in the present times.

Even today, water is being misused everywhere. Despite knowing and understanding the water crisis, efforts are not being made to save it. If India is not dealt with soon after the problem of mismanagement of water, then the conditions in the future will be even more frightening. There is no doubt that India's population and poverty are a big challenge in the management of water. Due to the continuous waste of water, the water level in the ground is falling. Now people do not get water in the well. Due to the low water level in the ground, the trees and plants are also not getting much. Many trees dry up in result a lot of damage to the environment. If water is wasted like this then the day is not far when battles will be fought for drinking water.

Water provision and pricing challenges began to receive attention during the 1990s when the international community's focus shifted to sustainable development with greater emphasis on the economic and environmental aspects of development. India is the world's largest groundwater extractor, which extracts the twenty-fifth of the world's groundwater use annually. Five of the world's 20 largest cities in water stress are in India, with Delhi in second place. India has $16 \%$ of the world's population and only $4 \%$ of the world's water resources, which are rapidly depleting. We should conserve water for future generations as it can be a big challenge for the country.

The need for water is changing human life. Whereas India has set a record of development within the 21st century, urbanization and industrialization together with population development have expanded the demand for water. It is a serious concern for human society. The water level within the ground is going down due to wastage of water. It has become difficult to get water within the well due to the low level of water within the ground, trees and plants are too not getting much. If water is wasted like this, at that point the day isn't far when the battle for drinking water will be battled and the drinking water will be sold at exceptionally costly costs. In spite of knowing and understanding the water emergency, water is being abused all over. In the event that the issue of water fumble isn't taken truly, at that point the circumstance will be disastrous within the future.

There is no doubt that India's population and poverty are a big challenge in the management of water. Increasing population and consequent increase in food production, increase in the agriculture sector and irrigation sector are leading to higher water use. Due to the excessive use of water resources, there is a scarcity of water in many parts of the country. Needless to say that water conservation is very important for the economic, social and cultural development of India.

India is an agricultural country whose economic development is linked to agriculture. Water management should be initiated from the agricultural sector as water is used most often in agriculture and misuse of water is a serious problem in irrigation. There is a belief in popularity that more water yields more, which is incorrect. Irrigation contributes 15-16 percent to the production of crops. Enough water for the crop means sufficient moisture in the soil. But irrigation is being used indiscriminately in the present agricultural system. $70 \%$ of the water used in the irrigation system is wasted as it develops from the ground surface.

Excess or under irrigation is harmful to both land and crops. Old practices of irrigation land through "flooding" should be avoided and replaced by mulching, cropping, planting of trees, use of fog or dew through net-surfacing trap or polythene sheet, contour farming, water transfer. The inter-living water system, canals divided into surplus areas by distillation. The farmers of the country are not unaware of the easy and inexpensive technique of recharging groundwater, they need encouragement. The farmer should be told that wherever there are springs on the land, it should be stopped as far as possible.

Both urbanization and industrialization are factors that play an important role in water scarcity. Rapid urbanization in India has dried up traditional water bodies like ponds and lakes. There is scope for industrial and water recycling and reuse. Recycling and reuse of water will reduce the demand for new supplies. Most advanced countries are now using more recycled water instead of supplying fresh water for industrial purposes. The use of freshwater for non-portable purposes will not only create a shortage of freshwater but will also pollute entire water bodies. There is scope for industrial and water recycling and reuse. Recycling and reuse of water will reduce the demand for new supplies. Most advanced countries are now using more recycled water instead of supplying fresh water for industrial purposes. The use of freshwater for non-portable purposes will not only create a shortage of freshwater but will also pollute entire water bodies.

Water savings can be achieved in the industry through a combination of changing behavior, modifying and/or replacing equipment with water-saving equipment to reduce overall water consumption and increase internal reuse. To assure the strategies, optimize water and minimize costs, it is important to assess current water use and set goals. 
In India, the industry is the second-highest user of water. The key sources of water for the industries and factories are groundwater and surface water. Groundwater has risen as the main source to meet the water requirements of industries. Industrial wastewater may be a by-product of industrial or commercial activities. The foremost viable strategies of industrial wastewater administration are ones that aim to recycle, reduce, and reuse when conceivable. The key to the issue lies within the successful administration of water management. Appropriate measures including progressed handle innovation; wastewater treatment; reuse of handle water for more than once; re-circulating of handle water within the same utilize for a number of times; rainwater harvesting; wasteminimization must be embraced.

Until the realization of the importance of water is in the minds of all of us, it is not possible to improve the situation on a theoretical level. For this, people will have to work according to the right management to save water, if they do not pay attention to water conservation in time, it may be that human existence can be threatened in the absence of water. A fundamental change in attitude is needed in the way water resources are managed, taking into account social equity and ecological sustainability. Mass awareness is needed for not only water use but also ways and means in which ordinary people can contribute towards its proper utilization and management of water resources.

We ought to begin utilizing various measures to moderate water from our home. Water-using propensities have to be changed. We got to spare the streaming water by trickling it into our house. Household water and vitality preservation are deeply connected: by sparing water we protect the vitality required to induce it into our homes and treat it. Household water preservation can be utilized in all sorts of private, public, and commercial buildings. Utilization of water-efficient plumbing, low-flow or sensor spigots and devices contributes to directing water and essentialness and reducing wastewater. In expansion, distinguishing and setting up spills inside the water system can save an extraordinary sum of water. Giving endowment on water-saving units, like water collecting unit for the house, retrofit, can be an effective approach conserving water.

The water crisis is also a problem arising out of human error. As human beings have been having to exploit nature with the progress of civilization. The old tradition of planting trees along the banks of ponds, ponds, should be revived. Every single drop of rainwater flowing over the land can be collected in the river by making check dams to stop drains. Similarly, the recharge of groundwater can be done by making stitches, trenches and cockpits to bring rainwater from home, farm, village, and town to the ground. It is also indispensable to maintain traditional watershed along with modern resources. To promote conservation, water supply should be metered and monetized. Awareness and water conservation programs about the importance of water and its availability can help to minimize water damage to a great extent.

Factories and Industries should be restricted to use pure water. The government should take concrete steps for this. There should be adequate arrangements for drainage from the factory so that they do not get messed up in clean water. Conservation of rainwater is an important step that should be kept as an essential criterion for each newly built house. Until the realization of the importance of water is in the minds of all of us, it is not possible to improve the situation on a theoretical level. For this, people have to work according to the right management to safeguard the water if they do not pay attention to water conservation during the time, then there is no wonder in the absence of water that the next World War is for water. Will be responsible, that is, the whole human society. The essence of all these analyzes is that constant governmental and non-governmental efforts are necessary for water management. It is a global crisis; therefore, considering it a widespread problem in the context of the whole world, the governments of every country must work together to form a solid policy, only then the future of humanity will be secure. Therefore, we must use it efficiently, optimally and with due care to avoid wastages.

India is an agricultural country whose economic development is linked to agriculture. Water management should be initiated from the agricultural sector as water is used most often in agriculture and misuse of water is a serious problem in irrigation. There is a belief in popularity that more water yields more, which is incorrect. Irrigation contributes 15-16 percent to the production of crops. Enough water for the crop means sufficient moisture in the soil. But irrigation is being used indiscriminately in the present agricultural system. $70 \%$ of the water used in the irrigation system is wasted as it develops from the ground surface. 


\section{SOURCES OF FUNDING}

This research received no specific grant from any funding agency in the public, commercial, or not-for-profit sectors.

\section{CONFLICT OF INTEREST}

The author have declared that no competing interests exist.

\section{ACKNOWLEDGMENT}

None.

\section{REFERENCES}

[1] Chatterjee S N Water Resources, Conservation and Management Atlantic Publishers \& Dist, New Delhi, 2008.

[2] Duggal, V K. "Drinking Water and Sanitation" Yojana, DAVP Govt of India, New Delhi, June 2005.

[3] Green Deborah. "Water Conservation for Small and Medium-Sized Utilities"

[4] Hoque Ferdous Sonia. Water Conservation in Urban Households, IWA Publishing 2014.

[5] Mazumdr, Dilip Kumar. "Irrigation Water Management- Principles and Practices", Prentice Hall of India, New Delhi, 2000.

[6] Peter E. Black Readings in Soil \& Water Conservation, MSS information Corporation, New York, 1974. 